\title{
Application Analysis of Game Teaching Method in College Football
}

\author{
Teaching
}

\section{Zhou Peng}

University of Electronic Science and Technology of China, Chengdu, 611731, China

Keywords: Game teaching method, College football, Teaching, Application analysis

\begin{abstract}
As we all know, football teaching is an important part of physical education, which plays a significant role in the development of students' physical and mental health. But, affected by traditional concepts, many colleges and universities do not pay attention to the optimization and improvement of teaching methods in the actual teaching, leading to the learning interest loss of students. In view of it, this article mainly aims at the application of game teaching method in college football teaching to provide some references for the relative researchers.
\end{abstract}

Under the background of the knowledge serving the social development, the country pays more and more attention to the comprehensive quality and practical ability. Physical education is an effective means to promote the healthy development of the whole body. Football teaching is one of the main contents of physical education, and the construction of its teaching methods and models is of great significance to the realization of the goal of physical education. Therefore, it is necessary to study and analyze the relevant personnel.

\section{Significance of Application of Game Teaching Method in College Football Teaching}

Strengthen the Cultivation of Comprehensive Ability and Practical Skills of Students. In the actual teaching process, it is not difficult to find that students tend to be less interested in football than other sports. Students for football knowledge and understanding of the basic ability also has a big gap. Therefore, we should be able to play the game teaching on students' ability to reduce the difference, to give students a sense of frustration, depending on the individual differences of students and the characteristics of the targeted teaching, better meet students' individual needs. In this kind of game teaching mode, we need to cultivate students' interest and improve the teaching efficiency and teaching quality. At the same time, in this interesting teaching, students can better feel the meaning of being respected and cared for, and stimulate students' enthusiasm for learning. This kind of method is more meaningful than the passive theory teaching.

Promote the Reform of Football Teaching in Universities. In the traditional teaching process, it is not difficult to find that colleges and universities only give students effective training of professional football skills, the physical and mental health of students and the lack of attention to hobbies. This will result in the lack of effectiveness and interest in college football class, it cannot get enough fun in the learning process, it is difficult to improve the skills of football all. At present, the relevant departments have paid more and more attention to the development of students' physical and mental health. In this context, the implementation of the game teaching method can make physical education more suitable for teaching reform needs, promote the overall level of the college football to improve, promote all-round development of students' psychological quality and 
physical quality. At the same time, it can help students to establish a stronger confidence and self-esteem. To a certain extent, it also promotes the teaching methods and teaching mode of effective depth and improvement.

Enhance the Professional Skill Level of University Students. In the actual teaching process, subject to the limitations of personal factors and basic conditions, students have a great deal of difference in the mastery, understanding and acceptance of football skills. Although a lot of students have mastered a certain degree of football, but there are no good skills. In this circumstance, colleges and universities in the setting process of football game, according to the actual situation, the development characteristics of the individual needs of students and the ability of effective judgment, so it can be more targeted to improve the students' football skills, and can make the research and practice in the actual process of obtaining more fun. In this way, students have fun at the same time in the interest of the game, but also to reduce the differences in the level of football to bring confidence psychology, to promote the balanced development of the standard of football, the students help each other and friendly learning environment has played a good role in promoting. In the process of game teaching, students' interpersonal skills and team awareness can be significantly improved, thus ensuring the balanced development of the overall level of football.

\section{Application Principles of Game Teaching Method in College Football Teaching}

Applied under the Background of EducationalPrinciplesandIdeas. We will use the game teaching method has important meaning and function, so in college football teaching, which can effectively improve the students interested in football, and can improve the soccer skills in a more positive and optimistic and relaxed atmosphere, greatly improve the students' learning interest in football. To this end, the relevant educational personnel in the practical application process, should be fully aware of the importance of college football teaching and education, we should be able to fully realize the teaching method applied to the most original purpose is to realize the students the best education, this is just a way to help students an important tool for improving the teaching effect and teaching means, therefore, we are in the process of application, to be able to fully apply the principle of education among them, and instill in the whole process, which will pay more attention to the teaching.

Effective Combination of the Interesting Nature and Educational Nature of Football. In the actual teaching process, it is not difficult to find, for college students, although they have been all-round development of heart health, but they still need effective interest to make it better into the actual teaching, therefore, we can improve the football teaching to conscious interest thus, to a certain extent, improve the students to master the football teaching and attention, and that it is willing to actively participate in the learning process of the whole college football, so to a certain extent, improve the quality of teaching and promote teaching only, to effectively achieve the goal. Therefore, teachers should be able to process the application of game teaching method in the education of interest and give the effective integration, follow the principle of interest, to set up practical teaching links and teaching mode according to the characteristics of the actual situation of students and teaching, so that students can be fully aware of the interest which contains, and the ability to students will be happy to participate in them.

Simplify the Whole Football Teaching. The reason why we set up the game teaching method, the main purpose is effective for the entire football teaching brings great fun, the teaching content of complex boring simple and specific and vivid, therefore, we should fully consider this point in the game, try to choose some simple game textbooks. And according to the interests of the students to give a reasonable adjustment, so that it can be the actual situation and the consistency and 
stability of great. Although some football game design model is also very creative, but the use of the equipment and the corresponding equipment has many, implementation is difficult, the implementation for the entire game teaching created great obstacles, therefore, we should be able to avoid this kind of situation occurs, should be careful to choose the game. To ensure consistency of teaching goals and teaching methods with high.

\section{Application Methods of Strategy Suggestions of Game Teaching Method in College Football Teaching}

Select the Game consistent with Teaching Content. In the actual teaching process, we will process the game teaching method effectively applied to the football teaching, then the relevant educators first need to do is to the actual situation of students' learning ability and learning for the analysis, and to fully consider various factors, so that can choose to develop more meaningful and games, we in the design of the game, to be able to make the entire game and the whole football teaching skills effectively to maintain consistency, according to the actual situation of teachers is the master and calibration skill requirements, and for different learning conditions, and different the effect of learning, to one of the problems of improvement and optimization, and thus to a certain extent, the related games for football teaching The significance and function of. In the process of game teaching, we should also be targeted to improve and optimize students' learning and development characteristics. The teacher is in the process of game teaching, according to the actual demand of game skills, aspects of reasonable design, so as to ensure the rationality of the design of the game, so that it can be consistent with education goals to better promote the game teaching method in football teaching the important significance and function, make students more willing to participate in the football teaching.

Do a Good Job in the Preparation of Football Teaching. In the actual teaching process, we should be able to fully aware of the significance of the preparatory work and the role, only to ensure the effect of preparation activities, can be targeted to improve the quality of students. Therefore, before we to teach football, to be able to attract students attention, let the student's attention quickly to focus on learning, so that it can work for the latter study and provide convenient conditions, therefore, we should according to the actual situation of the game preparation reasonable link set, can the rise of full consideration of students' interests, so as to ensure the comprehensive preparations for the game, by this way, can bring more students to join the specific learning process, teachers in carrying out the game before considering the objectives and characteristics of football teaching can be fully, so as to ensure the whole preparation activities the game's accuracy and readability. The relevant personnel in the process of education game design, teachers should be able to analyze in a timely and effective manner to students' personalities and corresponding characteristics, through a variety of science to coefficient on students' personality and preferences judgment, which can effectively ensure the students love for the game, so that it can effectively guarantee in the practice of the game during the later stage of the important effect, the effective content and details not only conforms to the goal of education, but also can get more popular to the students.

Optimize and Perfect the Corresponding Game Rules. In the actual process of education, relevant educational workers should be reasonable and effective arrangement of related games, teachers will be able to make a reasonable comparison of game teaching of them, before carrying out teaching activities, teachers should be able to respect the objective implementation, according to the actual situation, according to specific issues, specific analysis, and can develop accurate rules of the game. In the process of developing the game, we should be able to promote the students to 
participate in the game and in the process of practice, and teachers should according to the actual teaching effect and the activities of the state, the corresponding rules and improve the continuous optimization, let the students at the same time can be fully aware of all the activities of the details and rules. Also, teachers can according to the actual situation and effect of the game, constantly optimize and improve the corresponding rules of the game, which can guarantee the quality and effect of effective game. To a certain extent, it can effectively improve students' interest in learning, but also enable students to improve their skills in a safe and orderly environment.

Raise the Consciousness of Safe Games of Students. Any games and activities will be carried out on the health and safety as the background, we in the process of teaching game design, to increase the students' physical quality, but also to strengthen the ideological and moral awareness, we need to be able to give students the words for reasonable assurance, which can achieve the goal of teaching better. Therefore, we in the actual teaching process, we can on the students' behavior to give a reasonable and effective education standard, better in accordance with the requirements for the game, which to some extent reduce the security risks in the teaching, and strengthen students in the teaching process, team cooperation consciousness to achieve the ultimate goal of education.

\section{Conclusion}

To sum up, the game teaching method plays an important role in the university football teaching. It can not only improve the students' physical quality, but also improve the students' comprehensive quality. Relevant personnel should give them sufficient reinforcement in the actual teaching process. Teachers can properly select the game, prepare the game, develop the rules and strengthen the safety awareness to promote the effect of game teaching method in the teaching process to promote the realization of the teaching goal to a certain extent.

\section{References}

[1] Dong Jiukui, Discussion on Football Game Design in Football Teaching [J].Vocational Technology, 2016, 15(8): 78-81.

[2] Liu Chong, Wu Zuo, Research on the Application of the Game Method in theFootball Teaching in Higher Vocational Colleges [J].The Guide of Science \& Education, 2016(25): 104-105.

[3] Zhang Bihao, Wu Can, A Brief Analysis of Reasonable Application of Football Game in College Football Teaching [J].Bulletin of Sport Science \& Technology, 2016, 24(5): 65+94.

[4] Shang Yanfeng, Games Played in Football Teaching in Higher Vocational Colleges [J].Journal of Wuxi Institute of Commerce, 2014, 14(4): 96-99.

Zhou Peng, male,zhengzhou henan province, born in November 1981, master degree, teaching assistant.

Research direction: football training and teaching methods 